\title{
On the issue of inertial excitation of diagnostic low-frequency vibrations in pipelines of housing and communal services
}

\author{
$R$ Z Shakurova $^{1, *}, S$ Gaponenko ${ }^{1}$, and $A$ E Kondratiev ${ }^{1}$
}

${ }^{1}$ Kazan State Power Engineering University, Industrial heat power engineering and heat supply systems department, 51 Krasnoselskaya str., Kazan, 420066, Russia

\begin{abstract}
The article discusses and analyzes issues related to the diagnosis of the technical condition of pipelines for housing and communal services. The main attention is paid to the inertial excitation of diagnostic low-frequency vibrations in the pipeline wall using the developed device. The results of experimental studies are presented.
\end{abstract}

\section{Introduction}

Energy is one of the fundamental sectors of the Russian economy. This is due to the fact that all technological processes in industry, agriculture, transport and in all spheres of public service are associated with the consumption of large amounts of energy [1]. In this regard, much attention is paid to the reliability of the power system and the safe operation of power equipment. One of the areas of reliability assurance is equipment diagnostics in order to timely identify defects and their subsequent elimination [2-4].

\section{Formulation of the problem}

Regulation of issues related to the reliable and safe operation of production facilities and aimed at preventing accidents and hazardous situations in production processes is carried out by Federal Law No. 116-FZ "On industrial safety of hazardous production facilities" dated 21.07.1997.

In addition, the trouble-free operation of equipment and pipelines of industrial facilities ensures environmental safety and sanitary and epidemiological well-being of the population, prescribed by the Federal Law No. 170-FZ "On the Sanitary and Epidemiological Well-Being of the Population" dated 30.03.1999, Federal Law No. 7-FZ "On environmental protection "dated 10.01.2002.

Nowadays the problem of the wear and tear of utility infrastructure facilities and their technological backwardness is very acute. The general wear of the networks is about $70 \%$, which leads to a high accident rate and loss of water, heat, electricity during production and transportation to consumers [5-7]. In addition, such accidents entail large material costs, significant harm to the environment, and sometimes human casualties.
In this regard, it is necessary to control and the technical condition of the housing and communal services pipelines.

\section{Inertial excitation of diagnostic low- frequency vibrations}

Currently, some non-destructive testing methods are used for pipe diagnostics, such as ultrasonic testing, magnetic testing, capillary testing, but each of these methods allows detecting defects of a certain type, thus, these methods are not universal [8].

To assess the technical condition of pipelines, a universal technique and device for searching for various pipeline defects has been developed. The essence of the technique is to excite diagnostic low-frequency vibration vibrations in the pipeline wall using an inertial resonator, followed by registration of vibrations using a sensitive element and analyzing the obtained spectra [9].

Excitation of vibrations is carried out using a stand, the diagram of which is shown in Figure 1.

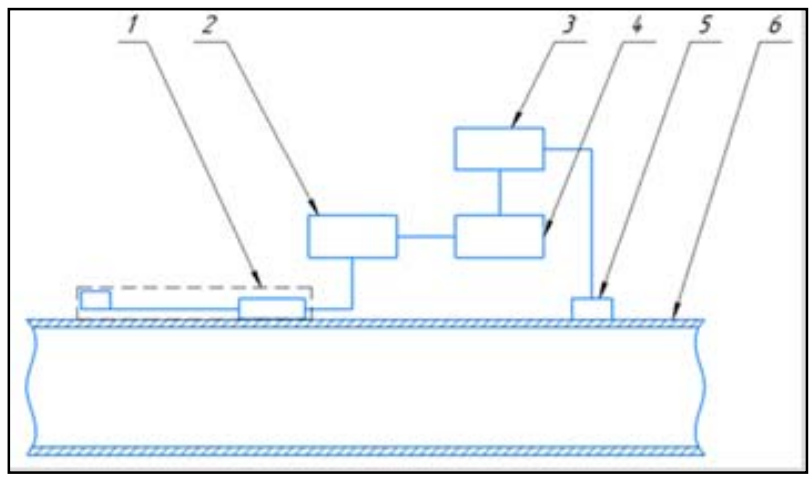

Fig. 1. Stand for the excitation of diagnostic low-frequency vibrations: 1 - inertial resonator; 2 - speed regulator; 3 analog-to-digital converter (ADC); 4 - personal computer; 5 sensitive element; 6 - pipeline.

\footnotetext{
* Corresponding author: shakurova.rz@gmail.com
} 
The main element of this stand is an inertial resonator, which allows generating diagnostic low-frequency vibration vibrations in the wall of the object under study.

An inertial resonator 1 and a sensitive element 5 are installed on the wall of the pipeline 6. A signal is sent from the personal computer 4 to the speed regulator 2 , which drives the inertial resonator 1 , consisting of an electric drive and an eccentric fixed on its shaft, during the rotation of which inertial forces arise, realizing a vibration effect on the walls of the pipeline 6 . The sensitive element 5 measures the parameters of the oscillations of the walls of the pipeline, the signal from it is sent through the analog-to-digital converter 3 to the personal computer 4 to register the oscillations of the pipeline walls excited by the inertial resonator and further analyze their parameters.

This provides the ability to vary the speed of the eccentric by means of an electric drive with numerical control, consisting of a personal computer, a speed controller and an inertial resonator.

Thus, by analyzing the parameters of the oscillations of the pipeline walls excited by the inertial resonator, recorded by the sensitive element, it is possible to identify and localize defects, i.e. determine the technical condition of the pipeline.

To control the vibration impact on the investigated pipe-wire, as well as to collect, store and process signals coming from the microphone, in the LabVIEW environment [10-12] a computer program "Condition monitoring system" was developed. Figure 2 shows the "Generation" program panel, where you can control and adjust the frequency of rotation of the inertial resonator. Figure 3 shows the program panel "Registration", in which the signals from the microphone are registered and these signals are converted into a spectrum for further analysis [13-15].

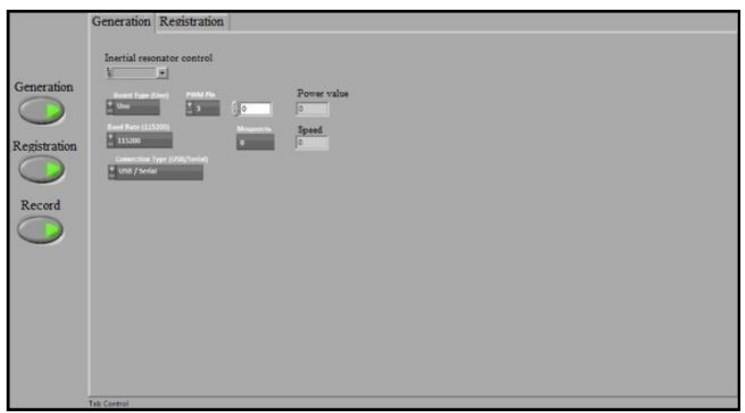

Fig. 2. Panel "Generation".

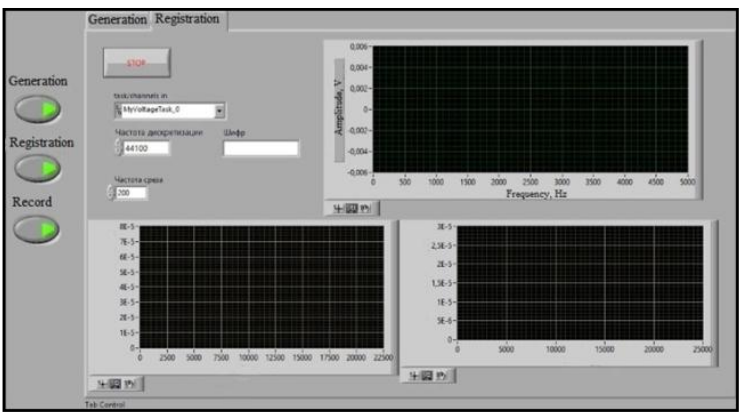

Fig. 3. Panel "Registration".

\section{Experimental researches}

Experimental studies were carried out on a fiberglass defect-free pipe with dimensions of $400 \times 72 \times 4$.

An inertial resonator was used to excite the oscillations. To register oscillations, a piezoelectric sensor was used, the signal from which was fed to a personal computer through an analog-to-digital converter manufactured by National Instruments. The analysis and processing of vibrations was carried out in the "Condition monitoring system" program.

The pipeline under study has different natural vibration frequencies found analytically in the ANSYS software package using modal analysis.

ANSYS is a finite element analysis software package that solves problems from a wide range of engineering activities. ANSYS has found application as a process modeling and forecasting tool in such industries as engine building, mechanical engineering, power engineering, automotive, shipbuilding, railroad transport, etc.

The results of calculating the natural vibrations of the pipeline are presented in Table 1.

Table 1. Results of modal analysis of the fiberglass pipe.

\begin{tabular}{|c|c|c|c|}
\hline $\begin{array}{c}\text { Oscillation } \\
\text { mode } \\
\text { number }\end{array}$ & $\begin{array}{c}\text { Frequency } \\
\mathbf{H z}\end{array}$ & $\begin{array}{c}\begin{array}{c}\text { Oscillation } \\
\text { mode } \\
\text { number }\end{array} \\
\end{array}$ & $\begin{array}{c}\text { Frequency } \\
\mathbf{H z}\end{array}$ \\
\hline 1 & 262,69 & 26 & 1554,5 \\
\hline 2 & 292,19 & 27 & 1626 \\
\hline 3 & 475,99 & 28 & 1682 , \\
\hline 4 & 498,7 & 29 & 1693,9 \\
\hline 5 & 527,59 & 30 & 1770,7 \\
\hline 6 & 532,88 & 31 & 1779,6 \\
\hline 7 & 623,76 & 32 & 1856,2 \\
\hline 8 & 656,43 & 33 & 1915,2 \\
\hline 9 & 710,81 & 34 & 1924,3 \\
\hline 10 & 862,45 & 35 & 1965,6 \\
\hline 11 & 864,03 & 36 & 2083,7 \\
\hline 12 & 1049,3 & 37 & 2088,4 \\
\hline 13 & 1065 & 38 & 2096,3 \\
\hline 14 & 1076,2 & 39 & 2129,5 \\
\hline 15 & 1135,8 & 40 & 2280,9 \\
\hline 16 & 1143,6 & 41 & 2303,7 \\
\hline 17 & 1231,1 & 42 & 2354,2 \\
\hline 18 & 1404 & 43 & 2383,9 \\
\hline 19 & 1410,3 & 44 & 2446,7 \\
\hline 20 & 1447,1 & 45 & 2456,2 \\
\hline 21 & 1453,8 & 46 & 2510,2 \\
\hline 22 & 1468,5 & 47 & 2608,9 \\
\hline 23 & 1483,4 & 48 & 2643,8 \\
\hline 24 & 1511,9 & 49 & 2648,3 \\
\hline 25 & 1549,2 & 50 & 2651,7 \\
\hline
\end{tabular}

For experimental studies, the most obvious frequency was chosen, equal to $864 \mathrm{~Hz}$, at which the maximum signal amplitude was observed.

Multiple experimental measurements were carried out with a change in the excitation points and vibration pickup points, at different points of the pipeline, subject to the rule: the distance between the inertial resonator 
and the piezoelectric sensor was the same and equal to the wavelength of the generated signal.

Figure 4 shows a photograph of the experimental stand.

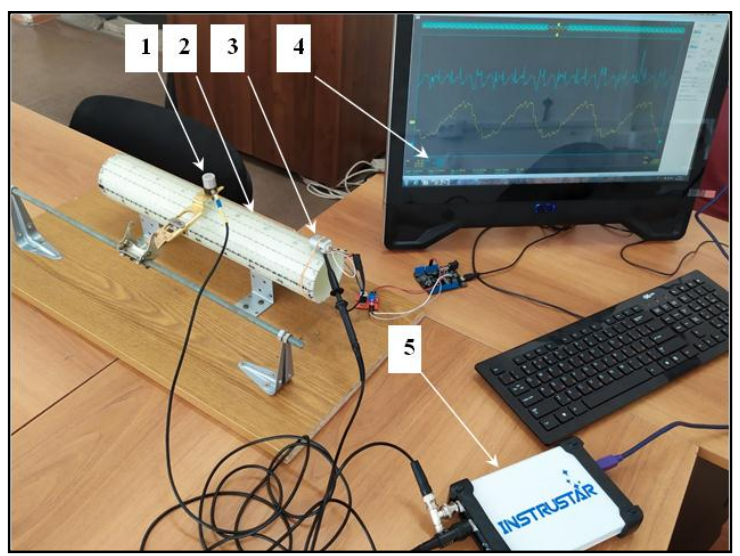

Fig. 4. Experimental stand with GRP pipe: 1 - piezoelectric sensor; 2 - investigated pipeline; 3 - inertial resonator; 4 personal computer; 5 - analog-to-digital converter.

In the course of experimental studies, a reference signal of $860 \mathrm{~Hz}$ was generated, and then an output signal was recorded using a piezoelectric sensor located at a distance of 1 wavelength.

Figure 5 shows the spectrum of the reference vibration signal for a 400x72x4 GRP pipe.

The spectrum on the OX axis shows the signal frequency in hertz $(\mathrm{Hz})$, on the $\mathrm{OA}$ axis the signal amplitude in volts (V).

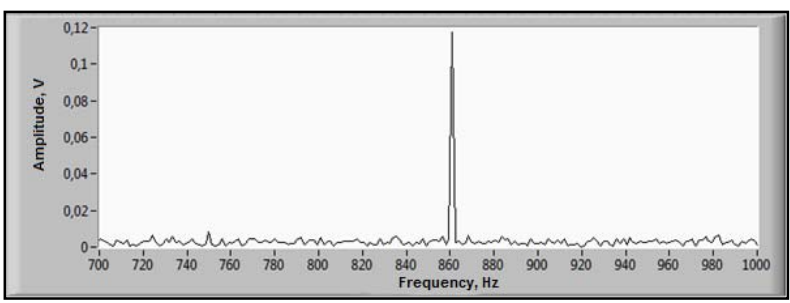

Fig. 5. The spectrum of the reference signal for the vibrations of the GRP pipe.

Figure 6 shows the spectrum of the output signal of GRP pipe vibrations recorded by the piezoelectric sensor.

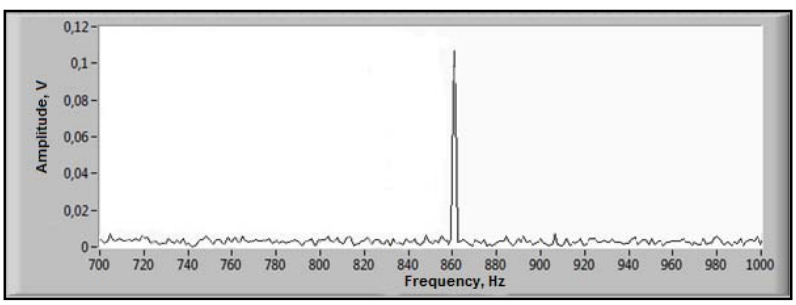

Fig. 6. Spectrum of the output signal of GRP pipe vibrations.

It can be seen from the spectra that the frequencies of the reference and output signals are the same, but the vibrational energy dissipates due to the passage through the wall of a defect-free pipeline. It is known that any violation of the material structure (discontinuity, crack, etc.), characterized as a defect, leads to an increase in the degree of dissipation of vibrational energy, respectively, the output signal recorded by the piezoelectric sensor will be noticeably weaker than the reference signal generated by the inertial resonator. By the degree of signal attenuation, one can judge not only the presence of a defect, but also its size.

\section{Conclusion}

The paper proposed a technique for assessing the technical condition of pipelines, presented a device for inertial excitation of vibrations in the wall of the object under study. The paper presents the results of experimental studies on a GRP pipeline with dimensions of $400 \times 72 \times 4$, which showed that the signal amplitude on a defect-free pipeline changes insignificantly. There is a process of normal dissipation of vibrational energy due to its passage through a solid, however, given that any defect is a change in the structure of the material, accordingly, the dissipation coefficient of vibrational energy at the site of the defect will be greater, which will lead to a weakening of the signal recorded by the piezoelectric sensor. The proposed method is the basis for creating a new measuring and diagnostic complex for vibration control of pipelines.

\section{References}

1. O.A. Makarov, E.A. Barbashina, Analiz problem sovremennoj elektroenergeticheskoj otrasli i strategicheskie puti ih resheniya $\mathrm{v}$ sootvetstvii $\mathrm{s}$ koncepciej energeticheskoj strategii do 2035 goda (Analysis of the problems of the modern electric power industry and strategic ways to solve them in accordance with the concept of the energy strategy until 2035), Vestnik VSUET, 2 (68), (2016)

2. S.P. Timoshenko, Kolebaniya $\mathrm{v}$ inzhenernom dele (Fluctuations in engineering), 1959

3. V.A. Yurko, Vvedenie $\mathrm{v}$ teoriyu obratnyh spektral'nyh zadach (Introduction to the theory of inverse spectral problems), 2007

4. G.M.L. Gladwell, Inverse Problems in Vibration. 2nd ed. (2004).

5. J. Zachwieja, Effectiveness of diagnosing damage to an industrial pump rotor by analysing its vibrations, Diagnostyka, Vol. 2, Iss.1, P.33-39 (2019)

6. J. Zachwieja, Pipeline stress analysis under supporting structure vibrations, Diagnostyka, Vol. 18, Iss.2, P.23 23-30 (2017)

7. Y. Stein, N. Zonova, I. Kubrak, L. Andreeva, Development and improvement of methods of diagnostics of heating systems in modern conditions, IOP Conference Series: Earth and Environmental Science, Vol. 90, Iss.1 (2017)

8. V. G. Kantsedalov, V. S. Korolev, V. N. Baltyan, Diagnostika tipovyh povrezhdenij truboprovodov i 
fiziko-mekhanicheskih svojstv kotlo-turbinnyh stalej energooborudovaniya TES i AES (Diagnostics of typical damage to pipelines and physical and mechanical properties of boiler-turbine steels of power equipment of TPP and NPP), DSTU (2018)

9. S.O. Gaponenko, A.E. Kondratyev, R.Z. Shakurova, Sposob inercial'nogo vozbuzhdeniya mekhanicheskih kolebanij $\mathrm{v}$ uprugoj obolochke (Method of inertial excitation of mechanical vibrations in an elastic shell), Patent RF No. 2705515, 07.11.2019

10. V.P. Fedosov, Cifrovaya obrabotka zvukovyh i vibrosignalov $\mathrm{v}$ LabVIEW (Digital processing of sound and vibration signals in LabVIEW), 2009

11. B.I. Kapranov, I.A. Korotkova, Spektral'nyj analiz v nerazrushayushchem kontrole (Spectral analysis in non-destructive testing), 2009

12. A.E. Kondratiev, S.O. Gaponenko, R.Z. Shakurova, S.A. Nazarychev, Acoustic-resonance method for control of the location of hidden hollow objects, IOP Conf. Series: Journal of Physics: Conf. Series (2019)

13. A.E. Kondratiev, S.O. Gaponenko, R.Z. Shakurova, S.A. Nazarychev, Information-measuring system for monitoring the location of underground gas pipelines on the basis of improved acoustic resonance method, IOP Conf. Series: Journal of Physics: Conf. Series (2019)

14. A.E. Kondratiev, S.O. Gaponenko, R.Z. Shakurova, R. Dimova, Improving the methodology for assessing the technical condition of equipment during the transportation of energy carrier in energy systems and complexes, E3S Web of Conferences (2019)

15. A.E. Kondratiev, S.O. Gaponenko, R.Z. Shakurova, R. Dimova, Improving the efficiency of energy complexes and heat supply systems using mathematical modeling methods at the operational stage, E3S Web of Conferences (2019) 